Neurosurg Focus 17 (1):E6, 2004, Click here to return to Table of Contents

\title{
Immediate and sustained relief of levodopa-induced dyskinesias after dorsal relocation of a deep brain stimulation lead
}

\author{
Case report
}

\author{
Ron L. Alterman, M.D., Jay L. Shils, Ph.D., Mark Gudesblatt, M.D., \\ AND Michele Tagliati, M.D.
}

Departments of Neurosurgery, Neurophysiology, and Neurology, Hyman-Newman Institute for Neurology and Neurosurgery, Yarmon Center for Parkinson Disease, Beth Israel Medical Center, New York; Albert Einstein College of Medicine, Bronx; and South Shore Neurological Associates, Bayshore, New York

\begin{abstract}
The authors demonstrate that high-frequency electrical stimulation dorsal to the subthalamic nucleus (STN) can directly suppress levodopa-induced dyskinesias. This 63-year-old woman with idiopathic Parkinson disease underwent surgery for placement of bilateral subthalamic deep brain stimulation (DBS) electrodes to control progressive rigidity, motor fluctuations, and levodopa-induced dyskinesias. The model 3389 DBS leads were implanted with microelectrode guidance. Magnetic resonance imaging confirmed proper placement of the leads. Postoperatively the patient exhibited improvement in all of her parkinsonian symptoms; however, her right leg dyskinesias had not improved. Based on their previous experiences treating levodopa-induced dyskinesias with subthalamic stimulation through the more dorsally located contacts of the model 3387 lead, the authors withdrew the implanted 3389 lead $3 \mathrm{~mm}$. Following relocation of the lead they were able to suppress the right leg dyskinesias by using the most dorsal contacts. The patient's dopaminergic medication intake increased slightly. These findings indicate that electrical stimulation dorsal to the STN can directly suppress levodopa-induced dyskinesias independent of dopaminergic medication changes. The 3389 lead may provide inadequate coverage of the subthalamic region for some patients.
\end{abstract}

KeY WoRdS • Parkinson disease

stereotactic neurosurgery - deep brain stimulation subthalamic nucleus $\bullet$ dyskinesia

High-frequency electrical stimulation (that is, DBS) in the region of the STN enhances the motor performance of patients with idiopathic PD and reduces their dopaminergic medication requirements. . $^{3,11-14,19,21}$ Each of the cardinal features of PD (tremor, rigidity, bradykinesia) is improved by DBS, as are levodopa-induced dyskinesias, which are a complication of chronic dopaminergic therapy. Because the clinical effects of subthalamic DBS are so similar to the effects observed after ablation of the STN in primates with 1-methyl-4-phenyl-1,2,3,6-tetrahydropyridine-induced parkinsonian symptoms $\mathrm{s}^{1,5}$ and because hyperactivity of the STN is a physiological hallmark of the parkinsonian brain, ${ }^{26}$ Benabid, et al., ${ }^{2,3}$ hypothesized that DBS achieves its effects by reversibly inhibiting STN activity. Furthermore, because both ablation and stimulation of the STN are known to induce hyperkinesis sug-

\footnotetext{
Abbreviations used in this paper: DBS = deep brain stimulation; $\mathrm{MR}=$ magnetic resonance; $\mathrm{PD}=$ Parkinson disease; $\mathrm{STN}=$ subthalamic nucleus.
}

gests that the amelioration of levodopa-induced dyskinesias after subthalamic DBS surgery is not a direct effect of high-frequency stimulation, but arises secondarily due to postoperative reductions in levodopa intake.,

Based on this thesis, Medtronic, Inc. (Minneapolis, MN) developed the model 3389 lead to increase the number of electrodes that can be placed within the STN. Like the original model 3387 lead, the 3389 lead is equipped with four 1.5-mm-long cylindrical platinum contacts (Fig. 1); however, on the 3389 lead the contacts are spaced just $0.5 \mathrm{~mm}$ apart, compared with the $1.5-\mathrm{mm}$ spacing found on the 3387 lead. Using the 3387 lead, one can position only two of the four stimulating contacts within the STN. The narrower interelectrode spacing of the 3389 lead permits one additional contact to be implanted within the nucleus, but at the cost of a 3-mm reduction in the lead's "effective stimulating length" (10.5-7.5 mm).

Satisfied with the results we had achieved with the 3387 lead, we did not adopt the 3389 lead when it became available. Moreover, we have found that different PD symp- 


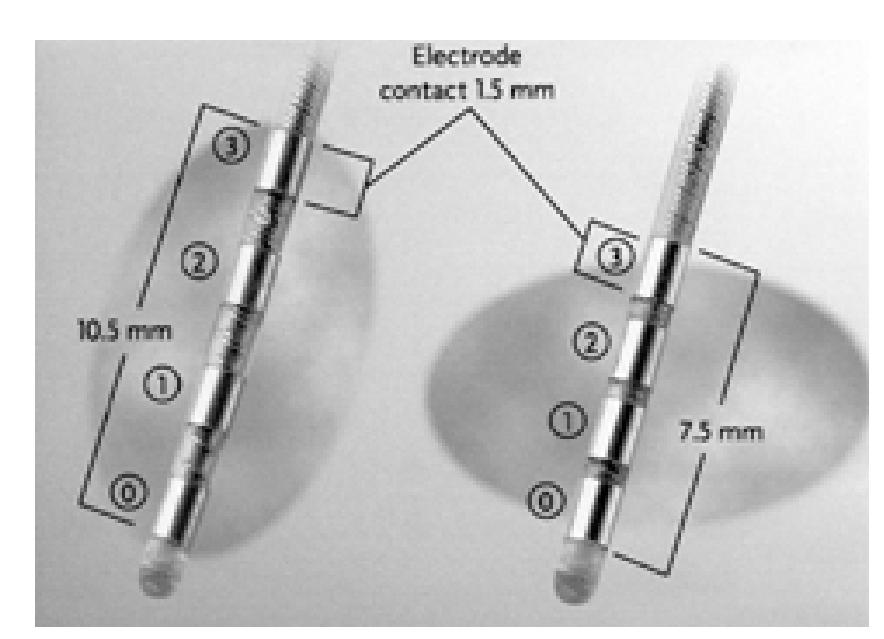

Fig. 1. Photograph showing the Medtronic, Inc., models 3387 and 3389 DBS leads. Each is equipped with four 1.5-mm-long cylindrical contacts; however, on the 3389 lead, which is depicted on the right side in the photograph, the interelectrode spacing is reduced from 1.5 to $0.5 \mathrm{~mm}$. This results in a $3-\mathrm{mm}$ reduction in the effective stimulating length of the lead.

toms are best treated through activation of contacts at different anatomical locations in the subthalamic region. ${ }^{24}$ In our experience, stimulation dorsal to the STN proper actively suppresses levodopa-induced dyskinesias, regardless of whether dopaminergic medications are reduced. ${ }^{24,25}$ We present an interesting case in which the 3$\mathrm{mm}$ dorsal relocation of an otherwise properly implanted 3389 lead dramatically reduced levodopa-induced dyskinesias that were unaffected by stimulation within the STN itself.

\section{CASE REPORT}

History and Initial Treatment. This 63-year-old woman has suffered from idiopathic PD since 1993. Her PD was diagnosed after she had experienced unilateral resting tremor for some months. A regimen of Sinemet was begun in July 1994 and yielded a good clinical response. Progressive gait difficulties and rigidity, worsening on/off phenomena, and the onset of dyskinesias necessitated bilateral subthalamic DBS surgery in December 2000; this procedure was performed at another institution by a reputable and experienced team. Model 3389 DBS leads were implanted with microelectrode guidance without complication. Postoperative MR imaging (Fig. 2 upper) demonstrated proper placement of the electrodes. Stimulation commenced in January 2001 and led to improvement in the patient's balance, gait, and tremor. Stiffness and left-sided dyskinesias were lessened; however, right-sided dyskinesias and rigidity persisted despite repeated stimulator adjustments.

Presentation and DBS Adjustment. We began treating the patient in February 2002. At that time she reported gait difficulties, poor speech, and worsening right leg dyskinesias. Multiple stimulator adjustments improved her rigidity and gait; however, her right-sided dyskinesias proved resistant, responding only to cathodal stimulation through the most dorsal contact (Contact 3) on the left and then
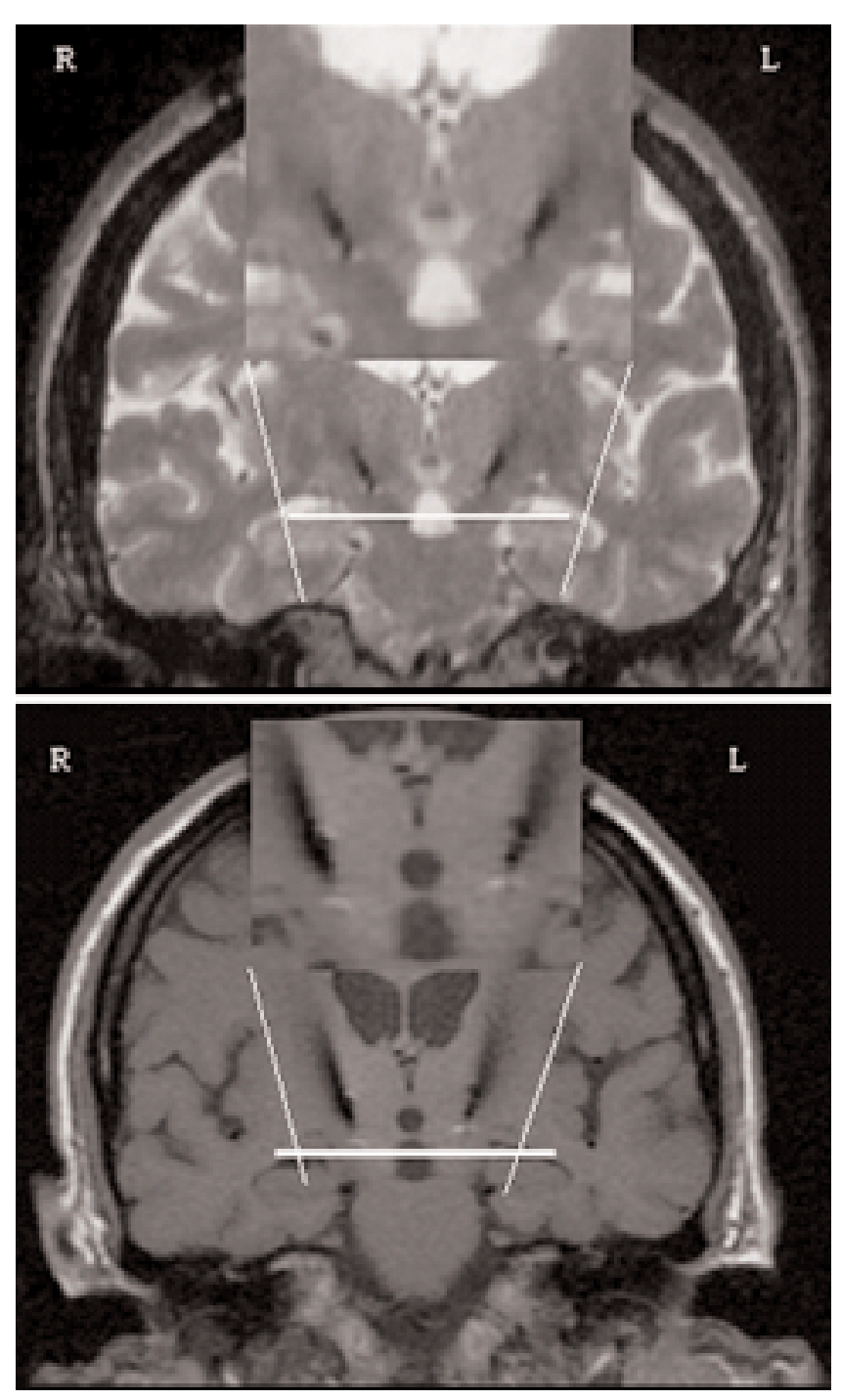

Fig. 2. Coronal $\mathrm{T}_{1}$-weighted MR images before (upper) and after (lower) dorsal repositioning of the left DBS lead; this lead was withdrawn $3 \mathrm{~mm}$ as measured directly during the procedure.

only minimally. Based on our previous observations, we postulated that by withdrawing the left DBS lead $3 \mathrm{~mm}$ (the difference in the effective stimulating lengths of the 3387 and 3389 leads) we could better control the patient's right-sided dyskinesias. The surgery was performed after delivery of a local anesthetic agent and mild propofol sedation. The 3389 lead was withdrawn $3 \mathrm{~mm}$ as measured directly; dorsal repositioning of the lead was confirmed with MR imaging (Fig. 2 lower). There were no complications.

Postoperative Course. Postoperatively, we were able to gain better control of the patient's right leg dyskinesias. In the attached videos we demonstrate the effects of unipolar cathodal stimulation through each of the implanted left subthalamic contacts on the patient's right leg dyskinesias before and after repositioning. After repositioning, stimulation through the dorsal-most contacts (Electrodes 2 and 3 ) yielded better control of the involuntary leg movements than was achieved preoperatively. The patient's medica- 
tion regimen and stimulator settings immediately before and 6 months after repositioning are given in Table 1 . Better control of the patient's levodopa-induced dyskinesias permitted a modest increase in her intake of dopaminergic agents.

\section{DISCUSSION}

This case is instructive for three reasons. 1) It demonstrates that electrical stimulation in the subthalamic region can directly suppress levodopa-induced dyskinesias independent of changes in dopaminergic therapy. 2) Dyskinesias were not suppressed by stimulation within the STN itself, but by stimulation dorsal to the STN, a region that includes the zona incerta, the $\mathrm{H}_{2}$ field of Forel, and the anterior thalamus. ${ }^{6,23} 3$ ) Rather than improving the results of subthalamic DBS surgery, the model 3389 lead may provide inadequate coverage of the subthalamic region for some patients, yielding suboptimal results even with leads that are accurately implanted within the dorsolateral STN.

The precise therapeutic target of subthalamic DBS is not known. If all of the clinical effects of this DBS treatment were generated through inhibition of the STN, only contacts that are positioned within the STN proper would be useful for therapy. Multiple investigators using a variety of localization techniques, however, have found quite the opposite: that the best clinical response may be generated by stimulation at a number of locations in the subthalamic region and that the majority of therapeutic contacts are located at the dorsal margin of the STN or dorsal to the nucleus entirely. ${ }^{10,15,16,22,27,28}$ Moreover, the anatomical position of the clinically most effective contact may be determined by the specific symptoms being treated. ${ }^{24}$

Similarly, the volume of neural tissue that is affected by an electrical stimulus and the physiological impact of that stimulus on both the intended target and on neural structures at a distance from it are largely unknown. Theories about the true mechanism of action of DBS remain somewhat speculative and include hyperpolarization blockade, modulation of dendritic inputs and/or local interneurons, and facilitation of axonal transmission. ${ }^{8} 18$ Mathematical models of stimulation within neural tissue are beginning to shed light on this important topic.

\section{TABLE 1}

Medication and stimulation regimen before and after repositioning of the left STN DBS lead in a patient with $P D^{*}$

\begin{tabular}{|c|c|c|}
\hline Regimen & Preop & 3 Mos Postop \\
\hline It generator settings & $\begin{array}{r}3.6 \mathrm{~V} / 60 \mu \mathrm{sec} / 185 \mathrm{~Hz} ; \\
\text { Contacts } 1-, 2+, 3-\end{array}$ & $\begin{array}{c}3.6 \mathrm{~V} / 120 \mu \mathrm{sec} / 185 \mathrm{~Hz} \text {; } \\
\text { Contacts } 2-, 3-, \mathrm{C}+\end{array}$ \\
\hline rt generator settings & $\begin{array}{r}3.6 \mathrm{~V} / 60 \mu \mathrm{sec} / 185 \mathrm{~Hz} \\
\text { Contacts } 1-, 2+, 3-\end{array}$ & $\begin{array}{c}3.6 \mathrm{~V} / 120 \mu \mathrm{sec} / 185 \mathrm{~Hz} \text {; } \\
\text { Contacts } 1-, 2+, 3-\end{array}$ \\
\hline daily medication intake & $\begin{array}{l}\text { levodopa } 550 \mathrm{mg}, \\
\text { ropinirole } 11 \mathrm{mg}\end{array}$ & $\begin{array}{l}\text { levodopa } 600 \mathrm{mg}, \\
\text { ropinirole } 11 \mathrm{mg}, \\
\text { entacapone } 1000 \mathrm{mg}\end{array}$ \\
\hline daily levodopa meq & 770 & 880 \\
\hline
\end{tabular}

* Better control of the patient's dyskinesias after repositioning allowed a modest increase in the patient's dopaminergic therapy, expressed as levodopa milliequivalents (see study by Razmy, et al.). Abbreviation: $\mathrm{C}=$ pulse generator case.
McIntyre, et al., ${ }^{17}$ found that cathodal stimulation at the dorsal margin of the STN delivers sufficient energy to propagate action potentials in axons up to $3 \mathrm{~mm}$ away. Moreover, the distribution and physiological effects of a delivered stimulus may be influenced by a number of factors, which will vary for every deep brain target. Grill and coworkers ${ }^{8,9}$ have demonstrated that a given stimulus can have opposing effects on different components of the same neuron. Specifically, stimulation at the parameters typically used for DBS can inhibit activity at the cell body while facilitating transmission along its axon. Furthermore, stimulation above a critical frequency induces regular axonal outputs that are informationally neutral. These reports expose our poor understanding of the effects and distribution of therapeutic electrical stimulation within the human brain and highlight the need for additional study.

Given the uncertainty surrounding the true therapeutic site(s) and mechanism(s) of action of subthalamic DBS and the suggestion that the effects of stimulation may be observed at least a few millimeters beyond an activated contact, and given that there is no published evidence to indicate that subthalamic stimulation through the 3389 lead yields superior results to stimulation with the 3387 , we believe that it is more prudent to use the 3387 lead to broaden coverage of the subthalamic region until a more precise target is identified.

\section{CONCLUSIONS}

High-frequency electrical stimulation dorsal to the STN can directly suppress levodopa-induced dyskinesias independent of alterations in dopaminergic medications. The Medtronic model 3389 DBS lead may provide insufficient coverage of the subthalamic region in some patients.

\section{References}

1. Aziz TZ, Peggs D, Sambrook MA, et al: Lesion of the subthalamic nucleus for the alleviation of 1-methyl-4-phenyl-1,2,3,6tetrahydropyridine (MPTP)-induced parkinsonism in the primate. Mov Disord 6:288-292, 1991

2. Benabid AL, Benazzous A, Pollak P: Mechanisms of deep brain stimulation. Mov Disord 17 (Suppl 3):S73-S74, 2002

3. Benabid AL, Benazzouz A, Hoffmann D, et al: Long-term electrical inhibition of deep brain targets in movement disorders. Mov Disord 13 (Suppl 3): 119-125, 1998

4. Benabid AL, Benazzouz A, Limousin P, et al: Dyskinesias and the subthalamic nucleus. Ann Neurol 47 (Suppl 1): S189-S192, 2000

5. Bergman H, Wichmann T, DeLong MR: Reversal of experimental parkinsonism by lesions of the subthalamic nucleus. Science 249:1436-1438, 1990

6. Carpenter MB: Core Text of Neuroanatomy, ed 3. Baltimore: Williams \& Wilkins, 1985

7. Fraix V, Pollak P, Van Blercom N, et al: Effect of subthalamic nucleus stimulation on levodopa-induced dyskinesia in Parkinson's disease. Neurology 55:1921-1923, 2000

8. Grill WM, McIntyre CC: Extracellular excitation of central neurons: implications for the mechanisms of deep brain stimulation. Thal Rel Syst 1:269-277, 2001

9. Grill WM, Snyder AN, Miocinovic S: Deep brain stimulation creates an informational lesion of the stimulated nucleus. Neuroreport 15:1137-1140, 2004

10. Hamel W, Fietzek U, Morsnowski A, et al: Deep brain stimulation of the subthalamic nucleus in Parkinson's disease: evalua- 
tion of active electrode contacts. J Neurol Neurosurg Psychiatry 74:1036-1046, 2003

11. Krack P, Batir A, Van Blercom N, et al: Five-year follow-up of bilateral stimulation of the subthalamic nucleus in advanced Parkinson's disease. N Engl J Med 349:1925-1934, 2003

12. Krack P, Benazzouz A, Pollak P, et al: Treatment of tremor in Parkinson's disease by subthalamic nucleus stimulation. Mov Disord 13:907-914, 1998

13. Krause M, Fogel W, Mayer P, et al: Chronic inhibition of the subthalamic nucleus in Parkinson's disease. J Neurol Sci 219: 119-124, 2004

14. Kumar R, Lozano AM, Kim YJ, et al: Double-blind evaluation of subthalamic nucleus deep brain stimulation in advanced Parkinson's disease. Neurology 51:850-855, 1998

15. Lanotte MM, Rizzone M, Bergamasco B, et al: Deep brain stimulation of the subthalamic nucleus: anatomical, neurophysiological, and outcome correlations with the effects of stimulation. J Neurol Neurosurg Psychiatry 72:53-58, 2002

16. Littlechild P, Varma TR, Eldridge PR, et al: Variability in the position of the subthalamic nucleus targeted by magnetic resonance imaging and microelectrode recordings as compared to atlas co-ordinates. Stereotact Funct Neurosurg 80:82-87, 2003

17. McIntyre CC, Mori S, Sherman DL, et al: Electric field and stimulating influence generated by deep brain stimulation of the subthalamic nucleus. Clin Neurophsyiol 115:589-595, 2004

18. Montgomery EB Jr, Baker KB: Mechanisms of deep brain stimulation and future technical developments. Neurol Res 22: 259-266, 2000

19. Ostergaard K, Sunde N, Dupont E: Effects of bilateral stimulation of the subthalamic nucleus in patients with severe Parkinson's disease and motor fluctuation. Mov Disord 17: 693-700, 2002

20. Razmy A, Lang AE, Shapiro CM: Predictors of impaired sleep and wakefulness in patients with Parkinson disease treated with older (ergot) vs. newer (nonergot) dopamine agonists. Arch Neurol 61:97-102, 2004
21. Rodriguez-Oroz MC, Gorospe A, Guridi J, et al: Bilateral deep brain stimulation of the subthalamic nucleus in Parkinson's disease. Neurology 55 (Suppl 6):S45-S51, 2000

22. Saint-Cyr JA, Hoque T, Pereira LC, et al: Localization of clinically effective stimulating electrodes in the human subthalamic nucleus on magnetic resonance imaging. J Neurosurg 97: 1152-1166, 2002

23. Schaltenbrand G, Wahren W: Atlas for Stereotaxy of the Human Brain, ed 2. New York: Thieme, 1977

24. Shils JL, Tagliati M, Miravite J, et al: Differential response of PD symptoms to active electrode position in the subthalamic nucleus during deep brain stimulation. Mov Disord 17 (Suppl 5):S193-S194, 2002 (Abstract)

25. Tagliati M, Huang N, Shils JL, et al: Immediate relief of levodopa-induced dyskinesias after deep brain stimulation of the subthalamic nucleus in Parkinson's disease. Mov Disord 17 (Suppl 5):S199, 2002 (Abstract)

26. Wichmann T, DeLong MR: Pathophysiology of Parkinson's disease: the MPTP primate model of the human disorder. Ann N Y Acad Sci 991: 199-213, 2003

27. Yelnik J, Damier P, Demeret S, et al: Localization of stimulating electrodes in patients with Parkinson disease by using a three-dimensional atlas-magnetic resonance imaging coregistration method. J Neurosurg 99:89-99, 2003

28. Yokoyama T, Sugiyama K, Nishizawa S, et al: The optimal stimulation site for chronic stimulation of the subthalamic nucleus in Parkinson's disease. Stereotact Funct Neurosurg 77: 61-67, 2001

Manuscript received May 27, 2004.

Accepted in final form June 8, 2004.

Address reprint requests to: Ron L. Alterman, M.D., Beth Israel Medical Center, 170 East End Avenue, New York, New York 10128. email: ralterma@bethisraelny.org. 